\title{
Complexidade institucional no campo esportivo de Santos após implantação do Promifae
}

\author{
Donald Veronico Alves da Silva ${ }^{1}$ \\ PATRICIA MARIA E. MENDONÇA ${ }^{1}$
}

\author{
${ }^{1}$ Universidade de SÃo Paulo / Escola de ARTes, CiÊnCIAS E Humanidades, SÃo PaUlo - SP, Brasil
}

\begin{abstract}
Resumo
Este trabalho observou como a complexidade institucional aumentou no campo esportivo da cidade de Santos após a introdução do Programa Municipal de Incentivo Fiscal de Apoio ao Esporte (Promifae). Para tanto, realizou um levantamento de dados primários e secundários, baseado em análise documental e entrevistas semiestruturadas, com uma abordagem exploratório-descritiva. Como contribuição, esta análise demonstra que a implementação do programa revela ambiguidades e conflitos de lógicas institucionais já existentes no campo esportivo, bem como amplia o alcance da lógica de mercado, exigindo das organizações participantes novas demandas para equilibrar essas diferenças. Como implicações práticas, verifica-se que o município de Santos não usa a lei e os recursos públicos de forma planejada e alinhada a uma política pública. A despeito disso, os benefícios do Promifae no campo esportivo são muitos, e a gestão pública deve buscar sua ampliação e integração com políticas esportivas mais bem desenhadas.
\end{abstract}

Palavras-chave: Políticas públicas. Leis de incentivo. Esporte. Lógicas institucionais.

\section{Institutional complexity in the field of sport after the implementation of a local tax incentive law in Santos, Brazil}

\begin{abstract}
This paper observed how institutional complexity has increased in the field of sports in Santos city after the introduction of Promifae, a local tax incentive law to encourage investment in sports. This instrumental case study has adopted an exploratory and descriptive approach, collecting primary and secondary data through semi-structured interviews and documental analysis. The study showed that the tax incentive law accentuates conflicts of institutional logic already existing in the field of sports, particularly between high performance sports and mass sports (for example, educational and recreational purposes). The law expanded the reach of the market logic, resulting in new demands for participating organizations which had to handle the conflicts of institutional logics. This paper verifies that the city of Santos does not use the law and public resources in a planned manner or aligned with other public policies. However, Promifae benefits the field of sports in Santos and and public management should seek its expansion and integration with better designed policies.
\end{abstract}

Keywords: Public policy. Tax incentive laws. Sport. Institutional logics.

\section{Complejidad institucional en el campo deportivo de Santos tras la implementación del Promifae}

\section{Resumen}

En este trabajo se observa cómo la complejidad institucional aumenta en el campo deportivo en de la ciudad de Santos luego de la introducción del Promifae (Programa Municipal de Incentivo Fiscal de Apoyo al Deporte). Para ello, se realizó un levantamiento de datos primarios y secundarios, basadoa en análisis documental y entrevistas semiestructuradas, adoptando un enfoque exploratorio-descriptivo. Como aporte, este trabajo demuestra que la implementación de la ley revela los conflictos de lógica institucional ya existentes en el ámbito deportivo entre el deporte de alto rendimiento y otras manifestaciones, además de ampliar el alcance de la lógica del mercado, exigiendo de las organizaciones participantes nuevas demandas para equilibrar estas diferencias. Como implicaciones prácticas, este trabajo verifica que el municipio de Santos no utiliza la ley y los recursos públicos de manera planificada y alineada con las políticas públicas. A pesar de ello, los beneficios del Promifae en el campo deportivo de Santos son muchos y la gestión pública debe buscar su expansión e integración con políticas deportivas mejor diseñadas.

Palabras clave: Políticas públicas. Leyes de incentivos. Deporte. Lógicas institucionales. 


\section{INTRODUÇÃO}

Diante da diversidade de arranjos possíveis de colaboração entre Estado, mercado e organizações da sociedade civil (OSCs), têm crescido na literatura estudos que analisam as dinâmicas locais e as demandas conflitantes enfrentadas pelos atores que performam essas atividades conjuntas e como elas levam a resultados não esperados, conflitos e resistências (Cloutier, Denis, Langley \& Lamothe, 2016; Meyer \& Hammerschmid, 2006). Políticas e programas públicos buscam desenhar ações e ambientes regulatórios que possam dar suporte a essas interações. Quando novas orientações para ações de programas públicos ou regulações são confrontadas com práticas anteriores no momento de sua implementação, as organizações envolvidas tentam acomodar o antigo e o novo, muitas vezes ancorados em diferentes lógicas institucionais (Thornton \& Ocasio, 2008; Thornton, Ocasio \& Lounsbury, 2012). Essas prescrições se mostram incompatíveis, e é necessário um processo de acomodação para lidar com a "complexidade institucional" (Besharov \& Smith, 2014; Kraatz \& Block, 2008; Pache \& Santos, 2010).

Este estudo examina como o campo esportivo da cidade de Santos depara com a implantação do Programa Municipal de Incentivo Fiscal e Apoio ao Esporte (Promifae) ${ }^{1}$ que completou 10 anos em 2020.

O esporte no país passou por diferentes momentos em que o Estado teve papel mais centralizador, tutelando e regulando confederações, federações e clubes, principalmente o de alto rendimento. Após a Constituição de 1988, abriu-se maior espaço para modalidades de esporte de participação e educacional (Bueno, 2008). No próprio campo esportivo já haviam disputas em torno de diferentes definições acerca do esporte e suas manifestações, que se desdobram em lógicas esportivas particulares. Com o advento das leis de incentivos, patrocinadores advindos do mercado ganham maior proeminência na destinação de recursos para o campo.

Este trabalho discute a complexidade institucional (Greenwood, Raynard, Kodeih, Micelotta \& Lounsbury, 2011), buscando compreender as mudanças para acomodar diferentes lógicas no campo esportivo da cidade de Santos após a criação do Promifae. Para tanto, traz uma seção com uma revisão sobre lógicas e complexidade institucional, bem como expressão do esporte na sociedade e suas lógicas subjacentes. Seguem-se, então, a seção metodológica e a descrição das mudanças ocorridas em Santos após a implantação do Promifae.

A metodologia utilizada para realizar o estudo foi a abordagem qualitativa, com a realização de uma pesquisa de natureza interpretativa. Ela se alinha às orientações epistemológicas comuns aos estudos neoinstitucionalistas que trabalham com as lógicas institucionais (Gibbs, 2009). Nessa perspectiva, a pesquisa realizou levantamento de dados primários e secundários, adotando uma abordagem exploratório-descritiva do campo esportivo da cidade de Santos relacionado à sua lei de incentivo ao esporte.

Como contribuição, este trabalho demonstra que a implementação do Promifae revela ambiguidades e conflitos de lógicas institucionais já existentes no campo esportivo entre esporte de alto rendimento e demais manifestações, bem como amplia o alcance da lógica de mercado, exigindo das organizações participantes novas demandas para equilibrar essas diferenças.

Como contribuições práticas, este artigo apresenta análises pertinentes a gestores públicos e esportivos, destacando limites da lei de incentivo ao esporte. Como contribuições para políticas públicas, ajuda a iluminar debates sobre leis de incentivos presentes no esporte, na cultura e na saúde.

\section{LÓGICAS E CAMPO INSTITUCIONAIS COMO CONSTRUTO ANALÍTICO}

Friedland e Alford (1991) consideram que as instituições, ao mesmo tempo que restringem a ação, fornecem espaço para escolha e fontes de agência e mudança. Ao contrário dos campos organizacionais de Dimaggio e Powell (1991), que buscam explicar a homogeneidade das organizações, Friedland e Alford (1991) conceituaram a sociedade como um sistema interinstitucional que possibilita a agência e a heterogeneidade das organizações.

\footnotetext{
${ }^{1}$ A palavra "programa" que faz parte da abreviação Promifae não corresponde à definição de conjunto de projetos que buscam os mesmos objetivos, estabelecem prioridade nas intervenções, são ordenados e alocam recursos comuns em políticas públicas. Trata-se apenas do título dado à lei.
} 
Um resgate e uma atualização dessa noção foram realizados por Thornton et al. (2012), que definem as lógicas institucionais como padrões históricos socialmente construídos de práticas materiais, presunções, valores, crenças e regras que os indivíduos produzem e que reproduzem sua sobrevivência material, organizam seu tempo e espaço, gerando significado para suas realidades sociais.

Os autores classificaram as ordens institucionais em mercado, religião, família, Estado, profissional, corporativa e da comunidade. O relacionamento por vezes contraditório entre as diferentes ordens institucionais e suas lógicas fornece um framework cognitivo-cultural aos atores e interfere na forma como as forças institucionais incidirão em determinado campo.

A partir daí, muitos estudos têm defendido que as organizações se encontram expostas a múltiplas lógicas institucionais, buscando compreender como essas lógicas interagem e como as organizações respondem a essas combinações, em especial quando elas estão em conflito (Besharov \& Smith, 2014; Greenwood et al., 2011; Kraatz \& Block, 2008; Pache \& Santos, 2010).

Kraatz e Block (2008) denominam de pluralismo institucional a situação em que organizações operam diante de múltiplas ordens institucionais, situação que pode levar à incoerência, ao conflito, à ambiguidade de objetivos e à instabilidade organizacional. Uma possível adaptação a tais demandas múltiplas traz desafios para simbolizar compromissos organizacionais com normas, valores e crenças num sistema social múltiplo.

Pache e Santos (2010) propõem um modelo de respostas organizacionais que leve em conta as configurações do campo organizacional e os processos políticos intraorganizacionais, os quais identificam que conflitos de lógicas institucionais, chamados pelos autores de demandas institucionais, podem levar as organizações à paralisia ou à quebra. Diferentemente de Kraatz e Block (2008), Pache e Santos (2010) destacam a importância do campo nas respostas das organizações.

Segundo os pesquisadores, compreender a forma com que as organizações responderão às lógicas institucionais requer entender quando seus conflitos possivelmente acontecerão em determinado campo institucional e de que maneira essas lógicas mediarão as relações entre organizações e indivíduos nesses espaços.

Greenwood et al. (2011) utilizam o termo "complexidade institucional" para caracterizar prescrições incompatíveis de lógicas institucionais múltiplas. Os autores enfatizam ainda que o campo e a forma na qual ele está estruturado é o local onde a natureza e a extensão da complexidade institucional que as organizações encararão serão moldadas. A complexidade institucional para esses autores varia de acordo com características dos campos - maduros ou emergentes, diferentes graus de estruturação formal, fragmentação e centralização. Besharov e Smith (2014) também fazem distinções acerca de características dos campos e da forma como lógicas conflitantes se apresentam.

Sobretudo após a introdução da perspectiva das lógicas institucionais, a terminologia utilizada pelos pesquisadores para se referir ao campo é abrangente. Nesse caso, as mais comuns são campos organizacional e institucional. Neste artigo, adotamos o termo "campo institucional". Thornton et al. (2012) destacam que, no campo institucional, seus participantes levam em consideração uns aos outros enquanto carregam consigo categorias inter-relacionadas de símbolos, práticas e vocabulários, transferindo-as para indivíduos e organizações que estão no interior desse campo. Os autores apontam ainda que os campos institucionais têm potencial para produzir e enfatizar contradições, conflitos e autonomia de práticas e formas, a depender do grau de alinhamento ou conflito das lógicas institucionais incidentes.

\section{O ESPORTE COMO UMA ORDEM INSTITUCIONAL E SUAS LÓGICAS}

O esporte pode ser classificado em antigo, moderno e contemporâneo (M. J. G. Tubino, Garrido e F. M. Tubino, 2007). O moderno resultou de um processo de modificação de elementos da cultura corporal do movimento das classes populares - como os jogos - e da nobreza inglesa a partir de meados do século XVIII (Bracht, 2005). O desenvolvimento e a expansão do esporte acontecem em estreita relação com a difusão da sociedade capitalista inglesa; com o processo de industrialização, urbanização e tecnologização dos meios de transporte e de comunicação; e com o aumento da burocratização ou organização formal.

Essa forma de prática corporal, orientada para o rendimento e a competição, vai se expandir para o continente europeu e se transformar no conteúdo hegemônico da cultura corporal de movimento em nível mundial ao longo do século XIX. Nesse contexto, o esporte se torna uma instituição específica e autônoma. Segundo Leonard (1998), a instituição esporte interage de diferentes maneiras com outras macroestruturas sociais, como as da economia, da família, da educação, da política e da 
religião, preenchendo funções como diversão e recreação, um meio de obter condicionamento físico e reduzir o estresse, além de uma forma socialmente aceita de expressar frustrações, conflitos, ansiedade, tensão e agressividade. Ele pode também gerar o sentimento de pertencimento a um grupo, a identificação com um coletivo, com uma nação, e a ocupação do tempo livre (Bracht, 2005).

M. J. G. Tubino et al. (2007) classificam como moderno a instituição esporte que surgiu no século XIX. Segundo Bracht (2005), tal modalidade foi propulsionada pelo movimento olímpico. $O$ alto rendimento domina o campo esportivo e é impermeável aos argumentos educacionais, da saúde e da confraternização.

Foi a partir da Carta Internacional de Educação Física e Esporte da Unesco, de 1978, contudo, que o entendimento de que o esporte não era destinado apenas às pessoas com talento e biotipos adequados é rompido. Surge o esporte contemporâneo, estabelecendo o direito de todas as pessoas a práticas esportivas e atividades físicas. Nessa nova perspectiva, para M. J. G. Tubino et al. (2007), o esporte passou a ser expresso pelas seguintes manifestações:

1. Esporte educação ou esporte na escola (esporte educacional e escolar);

2. Esporte na comunidade (esporte como lazer);

3. Esporte institucionalizado e esporte de desempenho (esporte de rendimento e de alto rendimento [EAR]).

Defendemos que a instituição esporte seja incluída ao conjunto de ordens institucionais do sistema interinstitucional classificadas por Thornton et al. (2012), mencionadas antes, pois sustentamos que um indivíduo ou uma organização, mesmo não pertencendo ou participando do campo institucional do esporte, estará de alguma forma envolvido por uma das manifestações esportivas citadas acima, ou seja, a do alto rendimento, a de participação ou a educacional.

Há uma particularidade acerca da instituição esporte. Aqui, propomos 3 sublógicas do esporte, que, apesar de estarem inter-relacionadas, são autônomas, têm características próprias e são comentadas a seguir.

A lógica do esporte de alto rendimento (EAR) compreende práticas esportivas em níveis elevados, que são acompanhadas de treinamentos de alto nível por atletas e equipes. O EAR funciona segundo regras de práticas esportivas nacionais e internacionais, e a legitimidade dos agentes é dada pelos resultados em competições, profissionais ou não. Os atores organizam seu tempo e espaço na busca de talentos, o que envolve seleção e exclusão dos praticantes à procura do perfil adequado. Esses praticantes são denominados atletas. Por ser a lógica predominante no campo, descobrir algum talento e alcançar resultados esportivos é altamente valorizado e prestigioso.

Na lógica do esporte educacional, evitam-se a seletividade e a hipercompetitividade de seus praticantes, que são orientados por princípios socioeducativos como inclusão, participação, cooperação, coeducação, responsabilidade, entre outros (M. J. G. Tubino et al., 2007). Nessa lógica, o valioso é a transformação social por meio do esporte: a inclusão social. Os atores organizam seu tempo e espaço buscando formas de proporcionar oportunidades para que todos possam praticar atividades esportivas regulares. Os praticantes, nessa lógica, são comumente chamados de alunos.

Já a lógica do esporte de participação compreende as modalidades desportivas praticadas com a finalidade de contribuir para suas integrações na plenitude da vida social, na promoção de saúde e educação, bem como na preservação do meio ambiente (M. J. G. Tubino et al., 2007). Não há restrição de idade ou aptidão. O esporte está relacionado ao lazer e ao tempo livre. O valioso nessa lógica é a promoção da saúde, a socialização e o lazer. Os atores organizam seu tempo e espaço buscando formas de melhorar a qualidade de vida dos praticantes.

Para melhor ilustrar as ordens institucionais do sistema interinstitucional, adaptamos os tipos ideais de Thornton et al. (2012), apresentados no Quadro 1 a seguir. Sua utilização é explicitada na seção metodológica.

Na literatura, há estudos que utilizaram a perspectiva das lógicas institucionais e a complexidade institucional no campo. Ainda que se valham de lógicas esportivas de forma diferente, entendemos ser importante mencionar Gammelsaeter e Solones (2013), Senaux (2011) e Gammelsaeter (2010). 


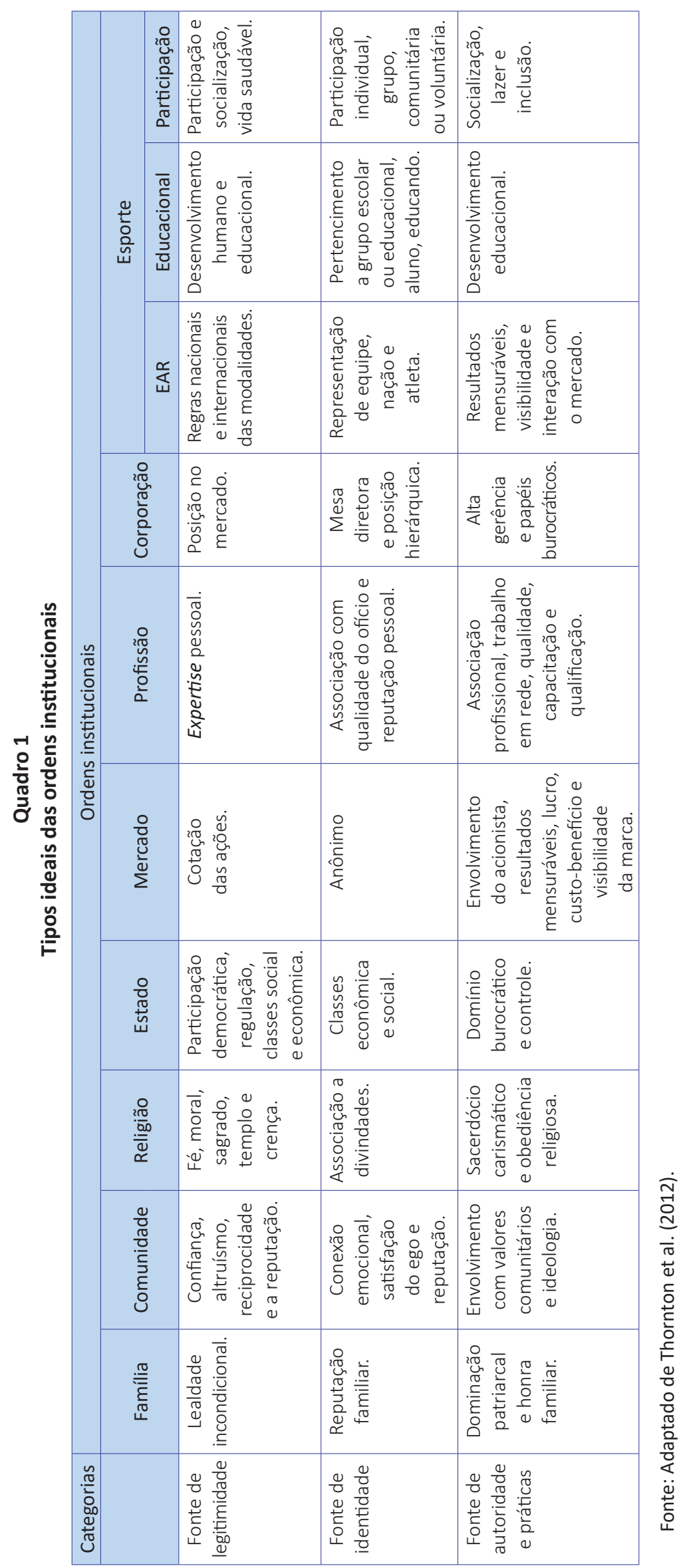




\section{METODOLOGIA}

Esta pesquisa é de natureza interpretativa, alinhada às orientações epistemológicas comuns aos estudos neoinstitucionalistas que trabalham com as lógicas institucionais, tendo o campo como nível de análise (Gibbs, 2009).

Zietsma, Groenewegen, Logue e Hinings (2017) observaram que a maioria dos trabalhos que lidam com campos não examina sistematicamente a natureza delas, usando-os apenas como pano de fundo para realizar outra análise, como a resposta das organizações. Não é o caso deste estudo, que tem como objeto de pesquisa o campo esportivo do município de Santos. Analisamos como um componente legal introduzido nele serviu para que um processo de realinhamento de lógicas acontecesse.

Thornton et al. (2012) destacam que, no campo institucional, seus participantes levam em consideração uns aos outros enquanto carregam consigo categorias inter-relacionadas de símbolos, práticas e vocabulários, transferindo-os para indivíduos e organizações que estão no interior desse campo. Os autores apontam ainda que os campos institucionais têm potencial para produzir e enfatizar contradições, conflitos e autonomia de práticas e normas.

No Quadro 1, sintetizamos as principais ordens institucionais, destacando o esporte como uma delas. O esporte está presente em várias dimensões da vida social, como economia, saúde e educação, e suas práticas, além de habilidades físicas, envolvem a transmissão de valores e normas. Dessa forma, buscamos compreender como essas lógicas incidem no campo esportivo da cidade de Santos, antes e depois do Promifae. A pesquisa realizou levantamento de dados primários e secundários em Santos, adotando uma abordagem exploratório-descritiva do campo esportivo da cidade relacionada ao programa (Gibbs, 2009).

Os dados primários da pesquisa vieram de duas fontes: análise documental dos processos arquivados do Promifae e entrevistas semiestruturadas com os atores-chave do campo. Os processos analisados foram os aprovados, captados e executados desde sua implementação, em 2010, até 2017 - os quais já tiveram todas as suas etapas finalizadas.

A análise dos processos aconteceu na Fundação Arquivo e Memória de Santos e na Secretaria Municipal de Esportes (Semes) da cidade. Foi montado um banco de dados destacando o nome da organização, o objeto do projeto aprovado, seu título e manifestação esportiva. Foram analisados também os relatórios de prestação de contas, sendo criada uma classificação confrontando os objetos com os relatórios de prestação de contas, contrastando com os tipos ideais e identificando com possíveis conflitos de lógicas e ambiguidade.

As entrevistas semiestruturadas com roteiro predefinido e questões abertas foram realizadas entre 2018 e 2019 . Essa identificação se baseou em inferência e no método snow-ball (Miles \& Huberman, 1994), em que se solicitou ao entrevistado a indicação de atores referências no campo. Todos os 14 entrevistados assinaram o termo de consentimento livre e esclarecido (TCLE). As entrevistas totalizaram 9 horas de gravações e foram realizadas com os seguintes entrevistados: setor Promifae e administração pública de Santos; empresas patrocinadoras e de consultoria; organizações esportivas, divididas entre clubes e outras OSCs. As entrevistas foram gravadas, transcritas, revisadas e, posteriormente, aprovadas.

A categorização para a análise de conteúdo dessas entrevistas se baseou em Bardin (2011) e Silva e Fossá (2015). Foram criadas categorias que buscaram descrever e identificar a história do campo e as lógicas presentes antes do Promifae, assim como as mudanças nas relações e nas intensidades das influências dessas lógicas após a lei no período estudado.

Em relação aos dados secundários, foram pesquisados em reportagens de jornais locais, legislações do município e no estudo de Almeida, Vanucci e Bastos (2019). As legislações locais estudadas foram a Lei Orgânica do Município de Santos; aquelas relacionadas a órgãos públicos esportivos, como o Conselho Municipal de Esporte (Comesp) e a Fundação Pró-Esporte (Fupes); bem como a lei e o decreto que instituíram e regulamentaram o Promifae. 


\section{ESPORTE EM SANTOS ANTES DO PROMIFAE}

Santos tem um campo esportivo bem-estruturado e definido, e isso não é recente. A cidade foi considerada a mais esportiva do Brasil pelo jornal O Globo, que, em 1955, realizou uma enquete entre 2373 municípios (Vaney, 1955).

No município, a vocação para o esporte continua nos dias atuais. Segundo informação no site oficial da prefeitura, a cidade conta com vários centros esportivos públicos e privados, campos de futebol, pistas de atletismo, piscinas, estádios, ginásios, quadras simples e poliesportivas. São promovidas atividades acessíveis para toda a população, apoiando eventos do setor e gerenciando o uso dos espaços esportivos municipais.

Além disso, a cidade conta com um vasto calendário esportivo ao longo do ano, sediando e promovendo eventos de nível regional, estadual, nacional e internacional. Há também os 3 clubes de futebol profissional que disputam diferentes campeonatos em âmbitos nacional e estadual.

Em relação a esta pesquisa, destacamos e fizemos a distinção entre organizações esportivas que chamamos de clubes e aquelas denominadas OSCs. Ressaltamos que clubes e OSCs fazem parte do campo esportivo da cidade, que também contempla outras organizações esportivas e satélites (Chelladurai, 2014).

Os clubes, apesar de também serem juridicamente associações civis sem fins lucrativos e um tipo específico de OSC, têm como objetivos principais a promoção do esporte - EAR, de participação ou educacional. Há aqueles para os quais os objetivos principais são o EAR, como o Santos Futebol Clube, a Portuguesa Santista e o Jabaquara Atlético Clube.

Outra categoria dos clubes são os sociais propriamente ditos. Estes, além de terem estruturas sociais para o lazer e contar com associados que pagam mensalidades, têm escolinhas de iniciação esportiva e equipes de rendimento com atletas federados em diferentes modalidades. De maneira geral, os clubes são entidades mais antigas e têm, desde sua criação, uma atuação bastante centrada no esporte.

As demais organizações ligadas ao esporte em Santos, as quais denominaremos de OSCs esportivas, são mais recentes e apresentam a lógica comunitária como predominante. Elas realizam ações gratuitas e de inclusão nas comunidades não só no campo do esporte, mas também em culturais, ambientais e educacionais.

A importância do esporte para a cidade se reflete em ações do poder público. O esporte está presente na Lei Orgânica do Município, a qual estabelece que Santos apoiará e incentivará as práticas desportivas como direito de todos, dando prioridade aos alunos de sua rede de ensino e estimulando a promoção de esportes nos clubes locais. Consta também que as ações do poder público e a destinação dos recursos orçamentários para o setor darão prioridade ao esporte educacional, comunitário e olímpico.

A efetivação das ações relacionadas ao esporte acontece por meio da Semes. Para assessorá-la, como órgão consultivo, foi instituído, em 1990, por meio da Lei Municipal no 710/1990, o Comesp. Conforme consta no item V de suas atribuições, membros do Comesp devem compor o Conselho Deliberativo da Fupes, fundação pública, instituída em 1996, pela Lei Complementar no 229 e que tem como finalidade a promoção do EAR.

A Fupes é desvinculada estruturalmente da Semes e tem o próprio presidente, indicado pelo prefeito, contudo deve prestar contas ao Comesp, cujo presidente é o secretário municipal de esportes. A fundação tem a prerrogativa de executar o projeto Adote um Atleta, que fornece auxílio financeiro a atletas que representam a cidade em competições oficiais - regionais, estaduais, nacionais ou internacionais. Esses atletas são indicados pelos clubes, que devem enviar um plano detalhado, com objetivos, metas, formas de direção e controle sobre os atletas que pretendam se habilitar para o recebimento do recurso (Decreto-lei complementar no 2.351, de 21 de dezembro de 2005). Os clubes também recebem auxílio da Semes e da Fupes quando disputam competições que não fossem os Jogos Abertos do Interior nem os Jogos Regionais.

Os clubes, muitos deles centenários, vivenciaram o período em que o Estado se relacionava com o esporte de forma centralizada, provendo recursos para EAR. Suas gestões eram baseadas no clientelismo e no amadorismo, em que seus diretores não eram remunerados, exercendo suas funções de forma voluntária e amadora, conforme descreveu Linhales (1996). Os clubes não se adaptaram à abertura do esporte a parcerias com empresas, iniciada na década de 1970, parando no tempo e contraindo várias dívidas, e alguns não existem mais ou venderam parte do patrimônio para sanar dívidas tributárias. 


\section{A IMPLEMENTAÇÃO DO PROMIFAE E A RECONFIGURAÇÃO DO CAMPO ESPORTIVO DE SANTOS}

A criação do Promifae aconteceu após a l e a ll conferências nacionais de esporte (CNE), sofrendo influência dos seus debates e resultados. A I CNE, realizada em 2004, propôs como objetivo a criação de uma Política Nacional do Esporte e do Lazer, entendendo a sociedade civil como instância essencial ao desenvolvimento do esporte e do lazer (Silva, Borges \& Amaral, 2015).

A II CNE aconteceu em 2006, com foco no direito social, na democratização e na universalização. Um de seus eixos temáticos foi o financiamento, e teve como marco a conquista da Lei de Incentivo ao Esporte federal (Lei no 11.438, de 29 de dezembro de 2006).

Durante as entrevistas, foi possível constatar que a Lei Federal de Incentivo ao Esporte serviu de inspiração para elaboração de legislações locais municipais e estaduais, e todas as que foram criadas antes de Santos serviram de inspiração para a criação do Promifae: "E eu levei para ele [o vereador] saber que existia já, já existia o movimento federal e que já existiam alguns municípios que já tinham essa, essa lei de, de incentivo que para algumas pessoas na época”. (ent.1).

Os clubes, precisando de recursos e auxílio para poderem representar a cidade em competições oficiais, mandavam seus representantes à Semes em busca de ajuda. O Promifae foi criado por um vereador que já havia exercido o cargo de secretário de esportes na cidade e regulamentado por meio da Lei Complementar no 615/2007 e do Decreto no 5.277, de fevereiro de 2009. Observa-se o destaque dado às manifestações de participação e rendimento:

Art. 1ㅇ, LC 615, 2007. I - contribuir para facilitar a todos os munícipes os meios para livre acesso às práticas esportivas; II - promover e estimular a revelação de atletas, com valorização de recursos humanos e conteúdos locais (grifo nosso); III - apoiar, valorizar e difundir competições esportivas do Município; IV - proteger a memória das expressões esportivas de Santos; $V$ - adquirir e preservar os bens e equipamentos para a prática esportiva; VI - desenvolver a consciência social e expor a contribuição do esporte na formação do caráter individual e coletivo do santista.

Em relação à sua implementação:

Art. 2ㅇ LC615/2007. Fica o Poder Executivo autorizado à emissão de certificados de incentivo fiscal de apoio ao esporte para realização de projetos esportivos - CIFE (grifo nosso), cujo montante global não poderá suplantar $0,2 \%$ da receita anual do município, proveniente da arrecadação do Imposto Predial e Territorial Urbano IPTU e do Imposto sobre Serviços de Qualquer Natureza - ISS.

É desses mesmos impostos que um eventual patrocinador - que podem ser pessoas físicas ou jurídicas - poderá deduzir até $20 \%$ do imposto devido nos exercícios vindouros. A lei também cria a Comissão Interdisciplinar de Avaliação e Concessão (Ciac), a fim de analisar os méritos orçamentário-financeiros dos projetos apresentados, composta por membros do governo e da sociedade civil.

Outro requisito exigido para poder propor projetos à lei é que os proponentes sejam entidades de natureza esportiva ou educacional. Por natureza esportiva, entende-se que deva constar no estatuto da organização a palavra "esporte".

Caso o proponente não tenha a capacidade técnica necessária para a elaboração do projeto ou a captação dos recursos, poderá contratar serviços de pessoas especializadas para fazê-lo, da mesma forma como é verificado na Lei de Incentivo à Cultura. Há, em Santos, empresas que cuidam de todas as etapas dos projetos: elaboração, captação, execução e prestação de contas.

Um último ator a destacar, introduzido pela lei, é o gerenciador dos projetos. Trata-se da pessoa representante do poder público, responsável por acompanhar e avaliar, tecnicamente, os projetos aprovados que estão sendo executados.

O Promifae pode ser dividido em 4 etapas: cadastro de proponentes e análise de projetos, captação de recursos, execução de projetos e prestação de contas.

O cadastro de proponentes e a análise de projetos envolvem envio e exame de vasta documentação pelo proponente. Essa etapa está rigorosamente alicerçada em procedimentos burocráticos, prática ligada à lógica do estado. É comum muitas OSCs, em geral, assim como OSCs esportivas, terem dificuldades nessa fase, que requer uma estrutura administrativa, jurídica e contábil mínima para manutenção da documentação. Boa parte dos clubes não logrou êxito nessa etapa por estarem inadimplentes com diversos impostos e taxas. 
Além desses documentos, é exigido um plano de trabalho completo, incluindo 3 orçamentos da planilha de gastos. Sobre essa etapa, um dos proponentes afirma:

Resumindo, a gente teve alguns problemas de manutenção, que fizeram com que o clube, não possuísse, não tirasse o AVCB, na data, no período marcado pra eu poder entregar os projetos. Então isso fez com que de 2017, pra cá, eu não consegui mais entregar projeto nenhum, o último foi em 2016, mas a gente sempre tentou entregar projeto, e a gente tentava (ent. 14).

A segunda etapa é a de captação de recursos. Para obter êxito, os proponentes devem conseguir convencer os patrocinadores de que, ao apoiar seus projetos, suas empresas terão retorno, seja por meio do custo-benefício ou da visibilidade da marca, seja por ações de responsabilidade social. Tais práticas estão ligadas à lógica do mercado. Em outras palavras, os proponentes devem ir a campo e vender seus produtos (projetos), momento em que a maioria encontra muita dificuldade: “Mas também não é só fazer o projeto. [...] O maior problema é a captação. Eu não faço isso e é muito difícil conseguir alguém que faça captação, muito difícil (ent.11)".

Importante frisar que a venda desse projeto sofrerá grande concorrência de outros proponentes, que buscam atingir o mesmo objetivo. Conforme veremos na Tabela 1 adiante, a quantidade de projetos apresentados e aprovados no Promifae foi elevada a cada ano. Com isso, aumentaram proporcionalmente a quantidade e as opções de escolha para destinar recursos.

Do ponto de vista da empresa patrocinadora, ela fará a seleção de projetos avaliando aumento do reconhecimento do público e reposicionamento da marca, reforço da imagem corporativa, envolvimento da empresa com a comunidade e obtenção de alcunha de responsabilidade social. A tendência é que elas patrocinem cada vez menos por meio de apoio direto, buscando o incentivo fiscal, cujo custo é 0, se comparado com o apoio direto (Cabral, 2010).

A burocracia do Estado também está presente nessa etapa. As empresas que se interessarem em patrocinar algum projeto aprovado no Promifae deverão enviar seus CNPJs e certidões negativas municipal, estadual e federal à Secretaria de Finanças (Sefin), a fim de serem analisados.

A terceira etapa é a execução do projeto, que envolve reportar ações para o poder público e patrocinadores, com conteúdo e formatos diferentes, o que se repete também na quarta etapa de prestação de contas. O Estado é quem fiscalizará o projeto, enviando o gerenciador para verificar a convergência entre o que foi aprovado e o que está sendo executado. O patrocinador envia relatórios ou recebe representantes das empresas, in loco, para constatar o bom andamento dos projetos e ver sua marca nos instrumentos de comunicação. Muitas vezes, a entidade precisa também lidar com manifestações esportivas com as quais não trabalhava antes. 


\section{RECONFIGURAÇÃO DE LÓGICAS NO CAMPO ESPORTIVO DE SANTOS}

Almeida et al. (2019) levantaram a quantidade de projetos submetidos no Promifae entre os anos de 2010 a 2017, conforme apontados na Tabela 1.

Tabela 1

Resultados dos projetos submetidos, aprovados e captados no Promifae

\begin{tabular}{c|c|c|c|c|c}
\hline Anos & $\begin{array}{c}\text { Projetos Submetidos } \\
\text { (PS) }\end{array}$ & $\begin{array}{c}\text { Projetos Aprovados } \\
\text { (PA) }\end{array}$ & $\begin{array}{c}\text { \% PA } \\
\text { Projetos Captados } \\
\text { (PC) }\end{array}$ & $\begin{array}{c}\% \text { PC } \\
(s / P A)\end{array}$ \\
\hline 2010 & 23 & 12 & 52,17 & 12 & 100,00 \\
\hline 2011 & 36 & 21 & 58,33 & 20 & 95,24 \\
\hline 2012 & 44 & 30 & 68,18 & 9 & 30,00 \\
\hline 2013 & 26 & 16 & 61,54 & 9 & 56,25 \\
\hline 2014 & 53 & 30 & 56,60 & 20 & 66,67 \\
\hline 2015 & 81 & 60 & 74,07 & 42 & 70,00 \\
\hline 2016 & 83 & 56 & 67,47 & 17 & 30,36 \\
\hline 2017 & 105 & 83 & 79,05 & 23 & 27,71 \\
\hline Total & $\mathbf{4 5 1}$ & $\mathbf{3 0 8}$ & $\mathbf{6 8 , 2 9}$ & $\mathbf{1 5 2}$ & $\mathbf{4 9 , 3 5}$ \\
\hline
\end{tabular}

Fonte: Almeida et al. (2019).

Podemos constatar que, dos 451 submetidos ao setor de protocolo do Promifae para análise, foram aprovados 308 , dos quais 152 conseguiram a captação de recursos e foram executados. O Gráfico 1 mostra a quantidade de projetos executados por manifestação esportiva.

Gráfico 1

Quantidade de projetos executados por manifestação esportiva

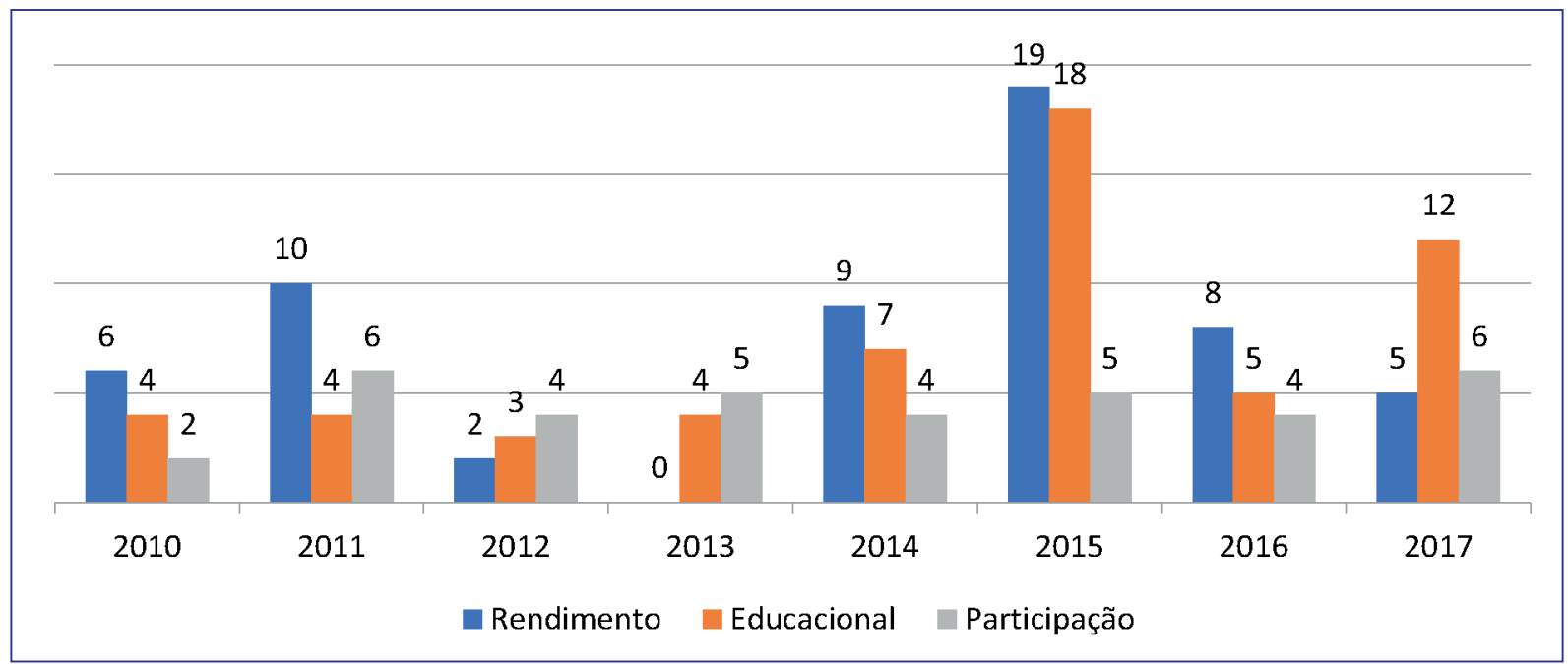

Fonte: Almeida et al. (2019).

Podemos constatar que os projetos de alto rendimento foram os que tiveram mais aprovações e captações, totalizando 59 , contra 57 de educacionais e 36 de participação. Na Tabela a seguir, é possível observar essas informações, em termos de valor captado, em que os projetos educacionais tiveram valor maior. 
Tabela 2

Distribuição do valor captado por manifestação esportiva

\begin{tabular}{c|c|c|c}
\hline Manifestação & $\begin{array}{c}\text { Quantidade } \\
\text { de Projetos }\end{array}$ & $\begin{array}{c}\text { Valor captador } \\
\text { por manifestação }\end{array}$ & $\begin{array}{c}\text { Porcentual do valor } \\
\text { total captado }\end{array}$ \\
\hline Educacional & 57 & $\mathrm{R} \$ 2.546 .172,82$ & $38,99 \%$ \\
\hline Rendimento & 59 & $\mathrm{R} \$ 2.345 .357,58$ & $35,91 \%$ \\
\hline Participação & 36 & $\mathrm{R} \$ 1.639 .428,21$ & $25,10 \%$ \\
\hline Total & $\mathbf{1 5 2}$ & $\mathbf{R} \$ \mathbf{6 . 5 3 0 . 9 5 8 , 6 1}$ & $\mathbf{1 0 0 \%}$ \\
\hline
\end{tabular}

Fonte: Almeida et al. (2019).

Baseado nos dados de Almeida et al. (2019), foram feitas análises adicionais dos 451 projetos submetidos entre 2010 e 2017. Verificou-se que os proponentes foram 28 pessoas físicas e 82 organizações esportivas distintas. Dessas, constatamos que apenas 7 (cerca de 8,5\%) foram o que denominamos clubes, 67 (cerca de 81\%) foram OSCs e 8 (cerca de $10 \%$ ), de outros tipos - como ligas desportivas -, demonstrando a força das OSCs no Promifae.

Complementando essas análises com as entrevistas realizadas e os exames do banco de dados levantados na Fundação Arquivo e Memória de Santos e na Semes, constatou-se que, entre as OSCs que acessaram o Promifae, tiveram destaque aquelas com atuação mais comunitária. Antes dessa lei municipal, muitas dessas OSCs tinham uma relação com os órgãos públicos sem relevância na área esportiva e passaram a ser os maiores proponentes de projetos.

De acordo com relatos de vários entrevistados, boa parte dos clubes fica impedida de enviar projetos com problemas de documentação. Como alternativa, profissionais que atuavam nesses clubes como dirigentes e/ou treinadores criam novas OSCs esportivas para acessar recursos. Houve ainda a aparição das organizações intermediárias, que auxiliam proponentes nas diferentes etapas do Promifae, inclusive sendo o elo entre estas e possíveis patrocinadores.

Diferentes empresas passaram a ter uma atuação mais direta na alocação de recursos. As patrocinadoras foram as que mais se fortaleceram no campo, podendo escolher, entre uma grande quantidade e variedade de projetos, os que mais se adequavam aos seus objetivos e políticas internas - buscar o custo-benefício ou a valorização da marca, ações de responsabilidade social junto à comunidade etc.

Ainda é possível verificar que boa parte de projetos de EAR continua disputando recursos com projetos educacionais e de participação no Promifae. Apesar de Santos já ter a Fupes, destinada a apoiar o EAR, a dominância dessa manifestação esportiva não foi totalmente quebrada. De todo modo, foi reconhecida maior participação de outras manifestações e migração de ações para áreas de maior vulnerabilidade.

Nota-se assim, eles têm a prioridade sim do local né, o local é importante, os locais que a, a secretaria de esporte tenha mais dificuldade de alcançar, que são Periferia né, os bairros mais, mais distantes os bairros com mais dificuldade né, até para entrar às vezes tem problema de traficante, tudo mais. Então os projetos nessas áreas realmente acabam tendo prioridade (ent 4).

O EAR e o esporte educacional, com recorte mais social, representam uma fonte de ambiguidade para os atores do campo. Nos processos analisados do Promifae, foi possível verificar muitos desalinhamentos entre o enunciado no objeto do plano de trabalho aprovado, o que era reportado ao fim dos relatórios de prestação de contas. 
Quadro 2

Exemplos de ambiguidade e conflitos em projetos no Promifae

\begin{tabular}{|c|c|c|}
\hline $\begin{array}{c}\text { Objeto descrito no plano } \\
\text { de trabalho }\end{array}$ & $\begin{array}{l}\text { Manifestação } \\
\text { esportiva }\end{array}$ & $\begin{array}{l}\text { Conflitos apresentados } \\
\text { nos relatórios finais }\end{array}$ \\
\hline Ensino de futebol & Educacional & $\begin{array}{l}\text { Projeto educacional. No entanto, no relatório se identificou } \\
\text { participação em campeonatos, jogos amistosos e seleção de } \\
\text { atletas, ações que não se caracterizam como educacional. }\end{array}$ \\
\hline $\begin{array}{l}\text { Proporcionar às crianças } \\
\text { oficinas socioesportivas } \\
\text { na área de futsal. }\end{array}$ & Educacional & $\begin{array}{l}\text { Apesar de educacional, tem como meta qualitativa identificar, no } \\
\text { mínimo, } 5 \text { potenciais jogadores e formar um time da instituição } \\
\text { para participar de outras competições fora do projeto. }\end{array}$ \\
\hline $\begin{array}{c}\text { Ensinar futsal, } \\
\text { taekwondo, muay thai, } \\
\text { hip hop esportivo e } \\
\text { basquete. }\end{array}$ & Educacional & $\begin{array}{l}\text { No relatório final, após a conclusão do projeto, observa-se } \\
\text { que foi criada uma equipe de competição que, como pontos } \\
\text { positivos, alcançou bons resultados - como a conquista de } \\
\text { campeonatos - e que, como pontos negativos, teve "alunos" } \\
\text { assediados por outros clubes. }\end{array}$ \\
\hline $\begin{array}{l}\text { Aquisição de } \\
\text { equipamento para aulas. }\end{array}$ & Educacional & Apesar de educacional, fala em revelar talentos e atletas. \\
\hline $\begin{array}{l}\text { Proporcionar o } \\
\text { desenvolvimento da } \\
\text { modalidade olímpica. }\end{array}$ & Alto rendimento & $\begin{array}{l}\text { Proporcionar chances de obtenção de melhor educação e } \\
\text { integração social. }\end{array}$ \\
\hline
\end{tabular}

Fonte: Elaborado pelos autores.

Outra fonte de ambiguidade é a preferência dos patrocinados, que também parece oscilar entre EAR e ações mais sociais. Alguns entrevistados mencionam essa confusão:

Esse ano a gente não quer competições a gente não quer patrocinar um atleta a gente quer projetos que atinjam o maior público-alvo, quanto maior o público-alvo, melhor para nós. Então você às vezes você transita numa areia movediça, porque você não sabe quais são os objetivos do poder público (ent 9).

A introdução do Promifae no município altera seu campo esportivo com a chegada de novos atores - OSCs com atuação comunitária que iniciam trabalho com esporte e novas OSCs fundadas por profissionais do esporte atuantes em clubes. A disponibilização de recursos públicos a partir de incentivos fiscais, com a decisão de escolha recaindo nas empresas, fortalece a lógica de mercado e as pressões por maior profissionalização. Surgem intermediários para fazer a ponte entre os proponentes e as empresas, assim como já era verificado nos projetos de incentivo à cultura (Belem \& Donadone, 2013; Ficheira, 2016).

A despeito do maior espaço ocupado pelas manifestações esportivas educacionais e de participação, o EAR permanece muito forte. Pela análise dos projetos exemplificada no Quadro 2, houve aumento de ambiguidade e ambivalência entre o EAR e as demais manifestações esportivas. A lógica do mercado se intensifica nas relações dos atores, já que a decisão de acesso aos recursos do Promifae recai nas empresas.

O campo esportivo de Santos experimenta aumento da complexidade, com a intensificação de ambiguidades e ambivalências entre as logicas institucionais (Greenwood et al., 2011; Kraatz \& Block, 2008; Pache \& Santos, 2010). Somado a isso, apesar de a cidade ter um histórico de forte presença no esporte, um aparato municipal de iniciativas, não conta com um plano municipal de esporte com diretrizes claras para a área. No Promifae, as decisões sobre aprovação dos projetos acabam ficando contingentes aos membros da CIAC e do secretário de esporte que estiver exercendo a função.

O que falta realmente é estar linkado com a política da Secretaria Municipal de Esporte, ou com uma política que possa beneficiar aí por exemplo outros objetivos como a da Fupes por exemplo. Então como não tem nada descrito, a análise de projetos ficava muito afeita aos componentes de uma comissão. Há uma comissão que analisa os projetos dentro da legislação e eles aprovam, para a o projeto poder captar. (ent 5). 


\section{CONSIDERAÇÕES FINAIS}

As leis de incentivo foram criadas para impulsionar áreas específicas de interesse público, otimizando a utilização de recursos com a participação de atores privados, e no Brasil contam com experiências nas áreas de cultura, esporte e saúde (Belem \& Donadone, 2013; Ficheira, 2016). Este trabalho não teve a intenção de ser uma pesquisa avaliativa de política pública, mas buscou avaliar o efeito do Promifae no campo esportivo de Santos, no sentido de seus efeitos simbólicos acerca dos entendimentos sobre esporte na sociedade e as respostas dos atores locais a essas mudanças.

Para realizar tal análise, valemo-nos da perspectiva das lógicas institucionais e focamos no campo esportivo de Santos como unidade de análise. Propusemos também a ordem institucional do esporte e suas respectivas simbologias no nosso modelo analítico (Quadro 1).

O Promifae completou 10 anos em 2020, e sua execução altera o campo esportivo na cidade com a introdução de novas organizações e novos recursos que promoveram mudanças na centralidade de certas lógicas no campo, intensificando ambivalência e ambiguidades já presentes, além de caracterizar maior complexidade institucional, situação em que uma ou mais lógicas exercem diferentes tipos de pressão em determinado campo institucional (Greenwood et al., 2011).

A lógica do mercado, antes presente no campo sobretudo mediante patrocínios de EAR, se intensifica, uma vez que passa pelas empresas as decisões sobre apoio a projetos. Demandas por alinhamento e fortalecimento de marcas, custo-benefício e resultados, como da lógica de mercado, juntamente com demandas das lógicas burocráticas de conformidade, criam pressões de profissionalização e respostas muitas vezes ambivalentes dos proponentes de projetos - necessidade de coletar e apresentar informações e relatórios distintos para as empresas e a Semes. A ambiguidade recai sobre alinhar demandas do EAR - busca de talentos, competição - com as manifestações educacionais e de participação - inclusão e cidadania. O campo esportivo de Santos se tornou, portanto, mais fragmentado entre as sublógicas esportivas e a lógica comunitária, com mais centralidade da lógica de mercado (Besharov \& Smith, 2014).

Algumas implicações práticas deste trabalho se alinham com achados advindos de considerações já realizadas sobre leis de incentivo na área cultural (Belem \& Donadone, 2013; Ficheira, 2016). A Lei de Incentivo à Cultura propiciou maior disponibilização de recursos na área, bem como a dinamização de algumas atividades e manifestações. Por outro lado, outras atividades e manifestações foram preteridas, sendo que a decisão sobre isso recaiu nos patrocinadores, em vez de ter sido estabelecido na política pública. Houve concentração geográfica de projetos/recursos, além de concentração em poucas organizações proponentes. Todo o processo de intermediação gerou requisitos de profissionalização antes inexistentes, fazendo com que intermediadores entre empresas e proponentes surgissem.

A maior parte desses efeitos foi verificada nas análises do campo esportivo de Santos após o Promifae. A despeito disso, os benefícios do programa no campo esportivo da cidade são muitos. Os diversos projetos educacionais e de participação aprovados e executados se deram em localizações onde a prefeitura, na maioria das vezes, não oferecia nenhuma atividade esportiva ao público beneficiário.

Se o município desenvolvesse uma política de esporte que buscasse integrar suas ações e fornecer diretrizes mais claras para a aprovação dos projetos, poderia contribuir para equilibrar os conflitos de lógicas, tornando mais fácil aos participantes lidar com a complexidade institucional. 


\section{REFERÊNCIAS}

Almeida, V., Vanucci, L. H., \& Bastos, F. C. (2019). A lei de incentivo ao esporte no município de Santos-SP: aplicação e captação de recursos de 2010 a 2017. Revista Intercontinental de Gestão Esportiva, 9(1), 21-37.

Bardin, L. (2011). Análise de conteúdo. São Paulo, SP: Almedina.

Belem, M. P., \& Donadone, J. C. (2013). A Lei Rouanet e a construção do "mercado de patrocínios culturais". Norus, 1(1), 52-61.

Besharov, M. L., \& Smith, W. K. (2014). Multiple institutional logics in organizations: explaining their varied nature and implications. Academy of Management Review, 39(3), 364-381.

Bracht, V. (2005). Sociologia crítica do esporte: uma introdução. Ijuí, RS: Editora Unijuí.

Bueno, L. (2008). Políticas públicas do esporte no Brasil: razões para o predomínio do alto rendimento (Tese de Doutorado). Fundação Getulio Vargas, Rio de Janeiro, RJ.

Cabral, B. F. (2010, abril 29). Leis de incentivo ao esporte atrelam arrecadação. Revista Consultor Jurídico. Recuperado de www.conjur.com. br/2010-abr-29/leis-incentivo-esporte-vinculam-beneficio-arrecadacao

Chelladurai, P. (2014). Managing organizations for sport and physical activity: a system perspective. Scottsdale, AZ: Holcomb Hathaway Publishers.

Cloutier, C., Denis, J. L., Langley, A., \& Lamothe, L. (2016). Agency at the managerial interface: public sector reform as institutional work. Journal of Public Administration Research and Theory, 26(2), 259-276.

Constituição da República Federativa do Brasil de 1988. (1988). Constituição de República Federativa do Brasil. Brasília, DF. Recuperado de http://www.planalto.gov.br/ccivil_03/constituicao/constituicao.htm

Decreto $n$ o 5.277, de 6 de fevereiro de 2009. (2009). Regulamenta a lei complementar no 615, de 18 de dezembro de 2007, que institui o programa de incentivo fiscal de apoio ao esporte - PROMIFAE para realização de projetos esportivos, cria o certificado de incentivo específico, e dá outras providências. Diário Oficial de Santos.

Dimaggio, P., \& Powell, W. (1991). The new institutionalism in organizational analysis. Chicago, IL: University of Chicago Press.

Ficheira, C. M. H. (2014). Projetos culturais: planos de comunicação, sustentabilidade e captadores de recursos no uso da Lei Rouanet. In Anais do Seminário Internacional de Políticas Culturais, Rio de Janeiro, RJ.

Friedland, R., \& Alford, R. (1991). Bringing society back in symbols, practices, and institutional contradictions. In R. Friedland, \& R. Alford (Eds.), The new institutionalism in organizational analysis. Chicago, IL: University of Chicago press.

Gammelsæter, H. (2010). Institutional pluralism and governance in "commercialized" sport clubs. European Sport Management Quarterly, 10(5), 569-594.

Gammelsæter, H., \& Solenes, O. (2013). Money in - brains out? Institutional logics affecting athletes' preparation for alternative careers. European Journal for Sport and Society, 10(3), 267-289.

Gibbs, G. (2009). Análise de dados qualitativos. Porto Alegre, RS: Artmed.
Greenwood, R., Raynard, M., Kodeih, F., Micelotta, E. R., \& Lounsbury, M. (2011). Institutional complexity and organizational responses. Academy of Management Annals, 5(1), 317-371.

Kraatz, M., \& Block, E. S. (2008). Organizational implications of institutional pluralism. In M. Kraatz, \& E. S. Block (Eds.), The handbook of organizational institutionalism. Thousand Oaks, CA: Sage publications.

Lei complementar no 229, de 13 de agosto de 1996. (1996). Autoriza o município a instituir a Fundação Pró-Esporte de Santos e dá outras providências. Diário Oficial de Santos.

Lei no 710, de 5 de dezembro de 1990. (1990). Institui o Conselho Municipal de Esportes - CONESP, e dá outras providências. Registrada no livro competente. Departamento Administrativo da Secretaria de Assuntos Jurídicos.

Lei no 2.351, de 21 de dezembro de 2005. (2005). Autoriza a Fundação Pró-Esporte de Santos a executar o Projeto "Adote um Atleta", mediante a concessão de auxílio financeiro aos atletas que especifica e dá outras providências. Diário Oficial de Santos.

Lei no 2.803, de 20 de dezembro de 2011. (2011). Disciplina o Conselho municipal de esportes - Comesp, e dá outras providências. Diário Oficial de Santos.

Lei no 11.438, de 29 de dezembro de 2006. (2006). Dispõe sobre incentivos e benefícios para fomentar as atividades de caráter desportivo e dá outras providências. Diário Oficial da União - Seção $1-29 / 12 / 2006$, Página 1.

Lei Orgânica do município de Santos/SP, de 5 de abril de 1990. (1990). Diário Oficial de Santos.

Leonard, W. M. (1998). A sociological perspective of sport. San Francisco, CA: Benjamin Cummings.

Linhales, M. A. (1996). A trajetória do esporte no Brasil: interesses envolvidos, setores excluídos (Dissertação de Mestrado). Universidade Federal de Minas Gerais, Belo Horizonte, MG.

Meyer, R. E., \& Hammerschmid, G. (2006). Administration in Austria. American Behavioral Scientist, 49(7), 1000-1014.

Miles, M., \& Huberman, M. (1994). Qualitative data analysis: an expanded sourcebook. Thousand Oaks, CA: Sage Publications.

Pache, A. C., \& Santos, F. (2010). When worlds collide: the internal dynamics of organizational responses to conflicting institutional demands. Academy of Management Review, 35(3), 455-476.

Senaux, B. (2011). Playing by the rules... but which ones? Sport, Business and Management - An International Journal, 1(3), 252-266.

Silva, A. H., \& Fossá, M. I. T. (2015). Análise de conteúdo: exemplo de aplicação para análise de dados qualitativos. Qualitas - Revista Eletrônica, 16(1), 1-14.

Silva, D. S., Borges, C. N. F., \& Amaral, S. C. F. (2015). Gestão das políticas públicas do Ministério do Esporte do Brasil. Revista Brasileira de Educação Física e Esporte, 29(1), 65-79.

Thornton, P., \& Ocasio, W. (2008). Institutional Logics. In P. Thornton, \& W. Ocasio (Eds.), The Handbook of Organizational Institutionalism. Thousand Oaks, CA: Sage publications. 
Thornton, P., Ocasio, W., \& Lounsbury, M. (2012). The institutional logics perspective: a new approach to culture, structure and process. Oxford, UK: Oxford University Press.

Tubino, M. J. G., Garrido, F. A. C., \& Tubino, F. M. (2007). Dicionário enciclopédico Tubino do esporte. Rio de Janeiro, RJ: Senac RJ.
Vaney, D. (1955, dezembro 14). Qual o município mais esportivo do Brasil. A Tribuna.

Zietsma, C., Groenewegen, P., Logue, D. M., \& Hinings, C. R. (2017). Field or fields? Building the scaffolding for cumulation of research on institutional fields. Academy of Management Annals, 11(1), 391-450.

Donald Veronico Alves da Silva

ORCID: https://orcid.org/0000-0003-3953-6737

Mestre em Gestão de Políticas Públicas pela Escola de Artes, Ciências e Humanidades da Universidade de São Paulo (EACH/USP).

E-mail: donaldveronico@gmail.com

Patricia Maria E. Mendonça

ORCID: https://orcid.org/0000-0002-5675-4261

Docente de Gestão de Políticas Públicas na Escola de Artes, Ciências e Humanidades da Universidade de São Paulo (EACH/USP).

E-mail: pmendonca@usp.br 